\title{
Correction to: Applied Physiology of Rugby League
}

\author{
Tim Gabbett ${ }^{1} \cdot$ Trish King $^{2}$. David Jenkins ${ }^{2}$
}

Published online: 16 September 2019

(c) Springer Nature Switzerland AG 2019

\section{Correction to: Sports Med 2008:38(2):119-138 https://doi.org/10.2165/00007256-20083 8020-00003}

The original article 'Science of Rugby League Football: A Review' by Tim J. Gabbett was published in Journal of Sports Sciences. 2005;23(9):961-76.

\section{Correction}

Our attention has been drawn to similarities between the two articles referred to above. The original J Sports Sci article published in 2005 reviewed all scientific papers on rugby league football to that point, including (1) physiological and anthropometric characteristics; (2) performance analysis; (3) injury epidemiology; (4) strength and conditioning; and (5) psychology. The aim was to provide a thorough review of the ways that sport science (including all sub-disciplines of sport science) had contributed to the understanding of the game. The Sports Med article published in 2008 reviewed all data to that point on the applied physiology of the sport. This paper differed in several ways from the earlier article: (1) much of the injury incidence information provided in the $J$ Sports Sci paper was not included; (2) important time-motion analysis data updating the demands of the game were included; and (3) data on the impact of physiological fatigue on tackling skill were included. Information on the physiological and anthropometric characteristics of players, which was originally excluded from the manuscript, was subsequently included on the request of one of the reviewers. Given the short time between the 2005 and 2008 publications, some crossover between the publications

The original article can be found online at https://doi. org/10.2165/00007256-200838020-00003.

Tim Gabbett

timg@broncos.com.au

1 Brisbane Broncos Rugby League Club, Fulcher Road, Red Hill, QLD 4059, Australia

2 School of Human Movement Studies, University of Queensland, Brisbane, QLD, Australia was inevitable, particularly as very few researchers were studying the sport at that time. Consequently, some of the conclusions relating to strength and conditioning were similar between studies. However, the overall conclusions and directions for future research for each paper were different, and as such each paper provides a unique contribution to the literature. Nevertheless, we acknowledge that text in a number of sections in the 2008 article overlapped with our previous 2005 article. 